\title{
How Good Are the Government's Deficit and Debt Projections and Should We Care?
}

\author{
$\underline{\text { Kevin L. Kliesen and Daniel L. Thornton }}$
}

\begin{abstract}
Each year, the Congressional Budget Office (CBO) publishes its Budget and Economic Outlook. The CBO's deficit projections for the current fiscal year (FY) and the next 10 FYs are widely followed because they provide an assessment of the medium-term budget outlook based on current law and a presumed path for the economy over the next decade. Admittedly, this task is more difficult because of the required assumption that the laws governing future outlays and revenues do not change. Nevertheless, given its nonpartisan nature and the CBO's well-respected staff of professional economists and budget analysts, its projections are closely followed. In this article, the authors update their 2001 assessment of the accuracy of the CBO's short- and medium-term budget projections by adding an additional 10 years of data. Such analysis is useful in light of the dramatic change in actual and expected fiscal policy, especially over the past few years. In addition, they investigate the extent to which the CBO's projection errors are affected by errors in forecasting key economic variables and the extent to which the errors relate more to inaccurate projections of revenues or expenditures. (JEL H60, H62, H68)
\end{abstract}

Federal Reserve Bank of St. Louis Review, January/February 2012, 94(1), pp. 21-39.

Kevin L. Kliesen is an economist and Daniel L. Thornton is a vice president and economic adviser at the Federal Reserve Bank of St. Louis. The authors thank Linpeng Zheng for research assistance.

(c) 2012, The Federal Reserve Bank of St. Louis. The views expressed in this article are those of the author(s) and do not necessarily reflect the views of the Federal Reserve System, the Board of Governors, or the regional Federal Reserve Banks. Articles may be reprinted, reproduced, published, distributed, displayed, and transmitted in their entirety if copyright notice, author name(s), and full citation are included. Abstracts, synopses, and other derivative works may be made only with prior written permission of the Federal Reserve Bank of St. Louis. 


\section{Kliesen and Thornton}

underprojecting the size of the deficit or overprojecting the size of the surplus. We concluded that "If the current projections are biased to a similar degree and policymakers choose to alter current tax and spending programs based on these projections, it is possible that the projected surpluses will never materialize" (p. 22).

Our conclusion proved accurate. Rather than being eliminated as projected, publicly held government debt increased to over $\$ 9$ trillion by 2010 . Much of the recent increase was a consequence of the government's attempt to ameliorate the effects of the financial crisis on output and employment; however, the failure of the projected surpluses to materialize was not the consequence of an unforeseen financial crisis. Publicly held government debt had increased to over $\$ 5$ trillion before the crisis. After 2000, revenues began to decline and expenditures began to rise and the projected surpluses morphed into actual deficits. Figure 1 shows this change in the federal surplus/deficit as a percent of gross national product (GNP) or gross domestic product (GDP) since 1800. The blue dashed line shows the CBO's budget projections from 2000. The figure shows there were relatively large deficits before 2009. The vertical line denotes 2011 , and the black dashed line shows the CBO's January 2011 budget projections over the next 10 years. The CBO projects that the deficit will stabilize at about 3 percent of GDP by 2021, according to its baseline projections. . $^{-}$

Current budget projections are the polar opposite of a decade ago: Over the past few years, U.S. budget deficits have been at levels previously attained only during the Civil War and the two world wars. Accordingly, in January 2011 the CBO projected that these large, unsustainable deficits would fall to more modest, although still historically large, levels over the medium term. However, since publication of the CBO's January 2011 baseline budget projections, the Budget Control Act of 2011 was signed into law in August 2011. ${ }^{4}$ According to the CBO, the act will potentially reduce the cumulative budget deficit by $\$ 2.1$ trillion over fiscal years (FYs) 2012 to 2021. Accordingly, in the CBO's baseline budget projections published in August 2011, the budget deficit as a share of GDP is projected to decline from about 9 percent in FY 2010 to 1.8 percent in FY 2021. In the January 2011 baseline, the CBO projected that the budget deficit would decline to 3.2 percent by 2021 .

How much confidence should the public and policymakers place in these new projections? As noted in our previous analysis, when the $\mathrm{CBO}$ constructs its baseline projections it cannotunlike private-sector forecasters-anticipate future changes in fiscal or monetary policy that affect future economic growth, outlays, and revenues. Instead, the $\mathrm{CBO}$ by law uses what is known as a "current services baseline." That is, it must assume that existing laws that govern outlays and receipts will prevail over the projection horizon. However, unexpected actions by policymakers to increase spending or change taxes are important sources of budget projection errors. Of course, this handicap is only one source of projection error. Model misspecification, which may bias the forecast of important economic variables, such as real GDP growth and inflation, and inaccurate demographic projections obtained from other government agencies are other sources of error. $\underline{5}$ In short, the $\mathrm{CBO}$ has a difficult task. Nevertheless, policymakers and others rely on its budget projections, which are generally viewed as an unbiased assessment of the medium-term budget outlook by market analysts.

This article provides an updated assessment of the accuracy of these budget projections in light of the dramatic change in actual and expected fiscal policy over the past few years. Specifically, we investigate whether a change has occurred in the accuracy and the bias of the CBO's 


\section{Figure 1}

\section{The Federal Surplus/Deficit as a Percent of GNP/GDP}

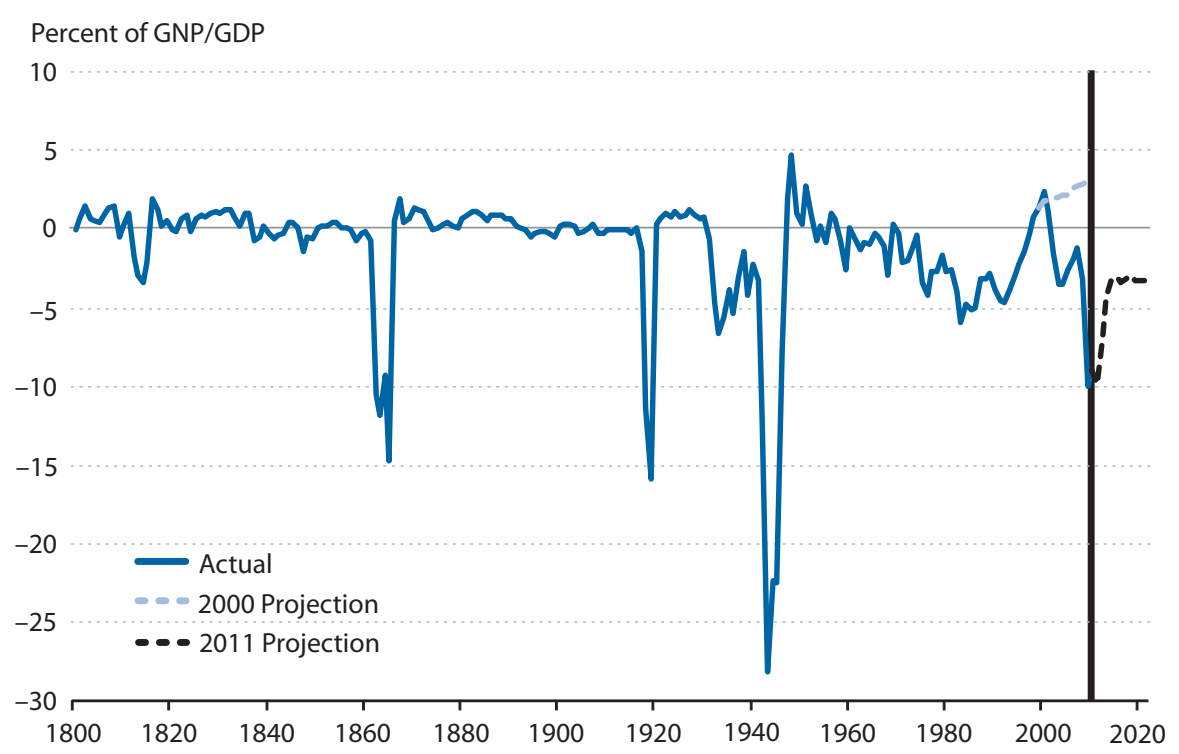

short- and medium-term projections relative to our previous analysis. In addition, the current analysis investigates the extent to which the CBO's projection errors are affected by errors in $\mathrm{CBO}$ forecasts of key economic variables, something we were unable to do in our previous work because the sample was too short. In addition, we decompose projection errors into revenue and expenditure errors, and further by the source of the revenue and expenditures errors, in an attempt to provide insight about the likely sign and magnitude of the errors associated with the current deficit projections. Our analysis begins with a discussion of U.S. deficits historically, focusing on the experience during the post-WWII period.

\section{THE HISTORY OF U.S. DEFICITS}

Figure 1 shows that large deficits relative to GDP have historically been associated with wars: the War of 1812, the Civil War, and World Wars I and II. By comparison with these wars, the deficits associated with the Korean, Vietnam, and Gulf wars were modest. The United States began running relatively large and persistent deficits in the 1970s. In the 24 years from 1947 through 1970, the average deficit as a percent of GDP was zero. In contrast, in the 37 years from 1971 through 2007, the average deficit as a percent of GDP was 2.5 percent. Moreover, there were only 4 years (10.1 percent of the years) during the latter period when there was a surplus compared with 10 years (41.7 percent of the years) in the earlier period.

An important question is why has the government run large and persistent deficits since 1971? We cannot answer that question per se, but we can ascertain whether large and persistent deficits are associated with increases in expenditures or decreases in revenue or some combination of both. Figure 2 shows government expenditures and revenues as a percent of GDP since 


\section{Kliesen and Thornton}

Figure 2

\section{Government Receipts and Outlays as a Percent of GDP}

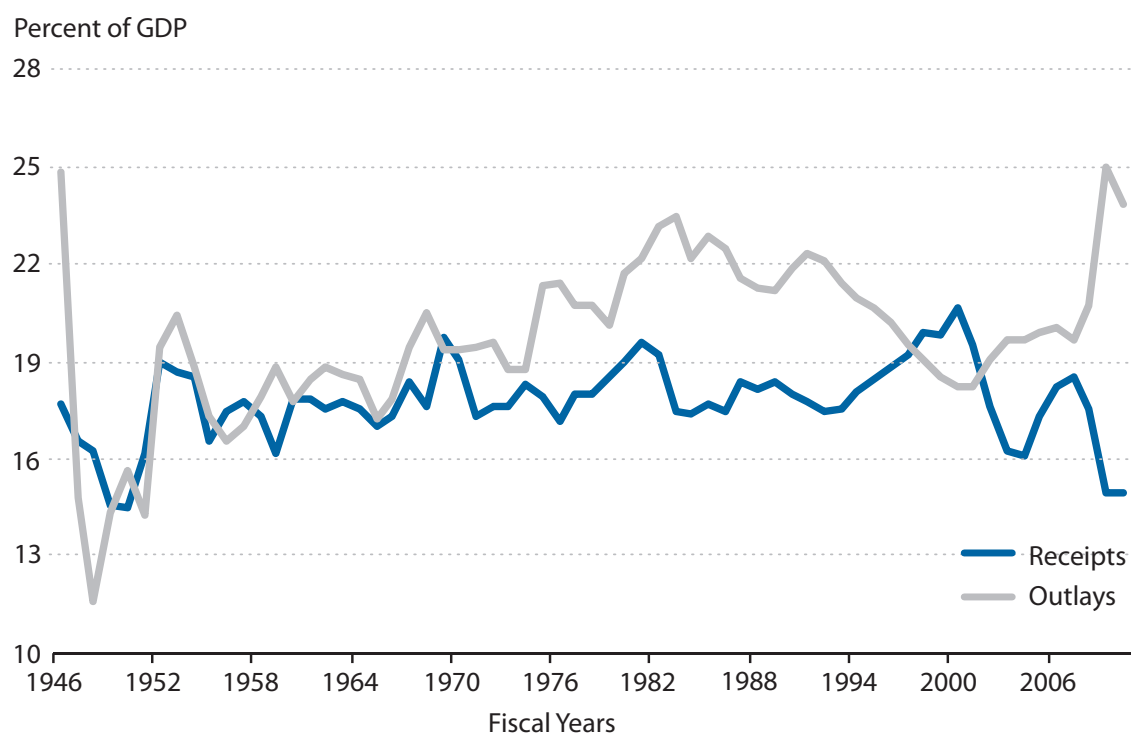

SOURCE: Office of Management and Budget and Haver Analytics.

\section{Figure 3}

The U.S. Cyclically Adjusted Budget Deficit

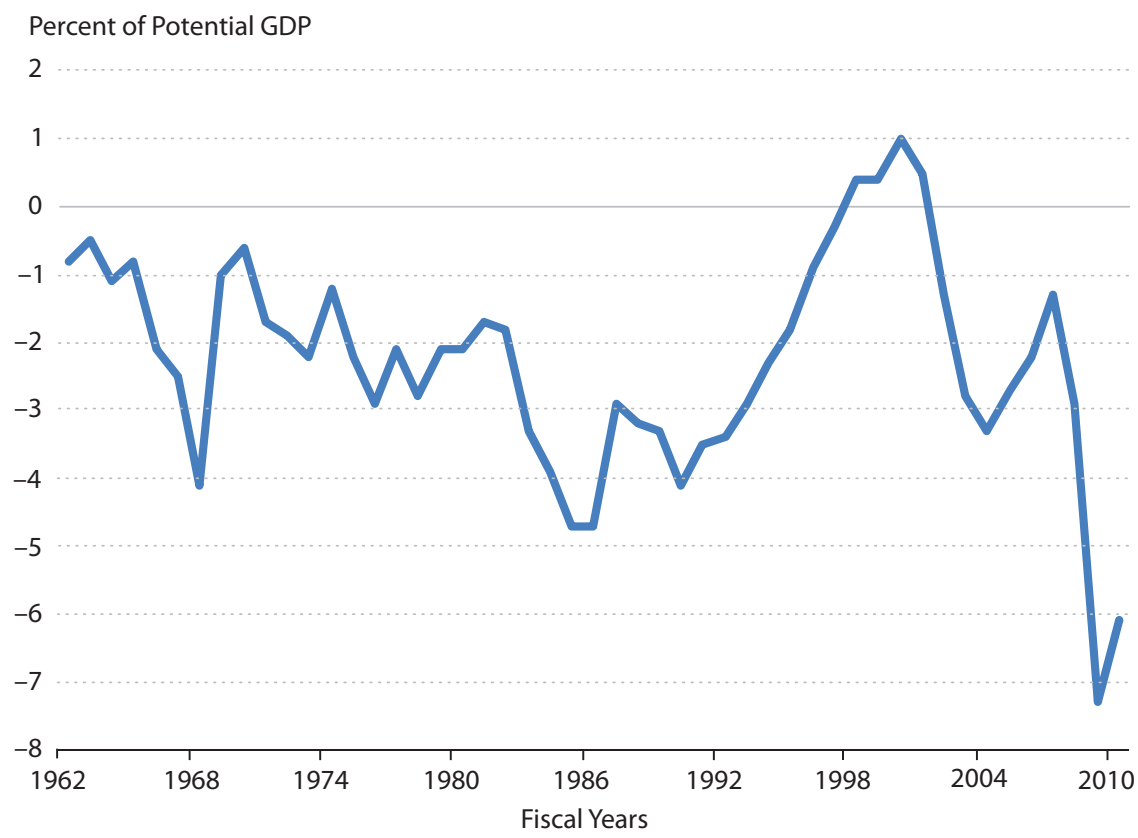

SOURCE: Congressional Budget Office. 


\section{Figure 4}

\section{Federal Government Receipts by Category (1948-2010)}

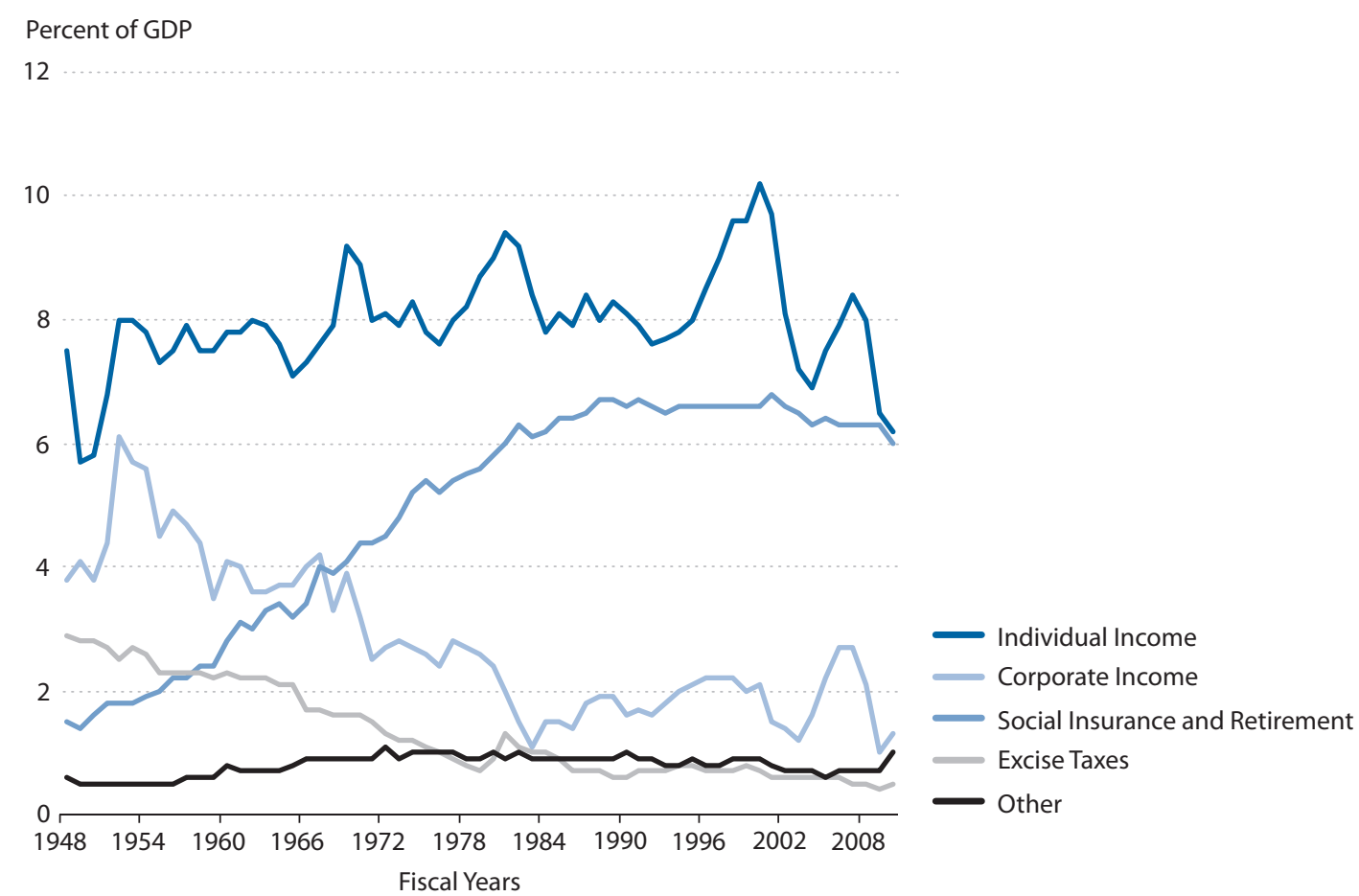

SOURCE: Office of Management and Budget.

1946. From the early 1950s until the late 1960s, revenues and expenditures were a relatively constant percent of GDP. From 1950 through 1970, revenue averaged 17.6 percent of GDP, while expenditures were only slightly higher, 18.2 percent. In contrast, from 1971 through 2007, revenue averaged 18.2 percent of GDP, while expenditures averaged 20.6 percent. Indeed, the difference between revenues and expenditures, 2.4 percent, is nearly equal to the 2.5 percent average deficit as a percent of GDP over the period. Hence, essentially the entire average deficit over the 19712007 period can be attributed to an increase in expenditures relative to revenues. $\underline{6}$

In response to persistently larger budget deficits, Congress enacted several reforms to the discretionary side of the budget process, such as the Gramm-Rudman-Hollings Balanced Budget and Emergency Deficit Control Act of 1985 and the Budget Enforcement Act of 1990, which instituted "pay-as-you-go" (PAYGO) rules. $\underline{7}$ None of these reforms has permanently reduced the deficit to its pre-1971 levels, though they may have had a temporary effect. Indeed, as seen by the cyclically adjusted (structural) budget deficit (Figure 3), the structural budget deficit increased from a little less than 1 percent of potential GDP in 1962 to a little less than 5 percent of potential GDP in 1986.. The structural deficit then declined, reaching a positive 1 percent in 2000, before falling sharply thereafter.

The previous analysis provides little insight into why government spending increased during the period. Considering the source of revenues and expenditures offers some insight into this 


\section{Figure 5}

\section{Federal Government Expenditures by Category (1948-2010)}

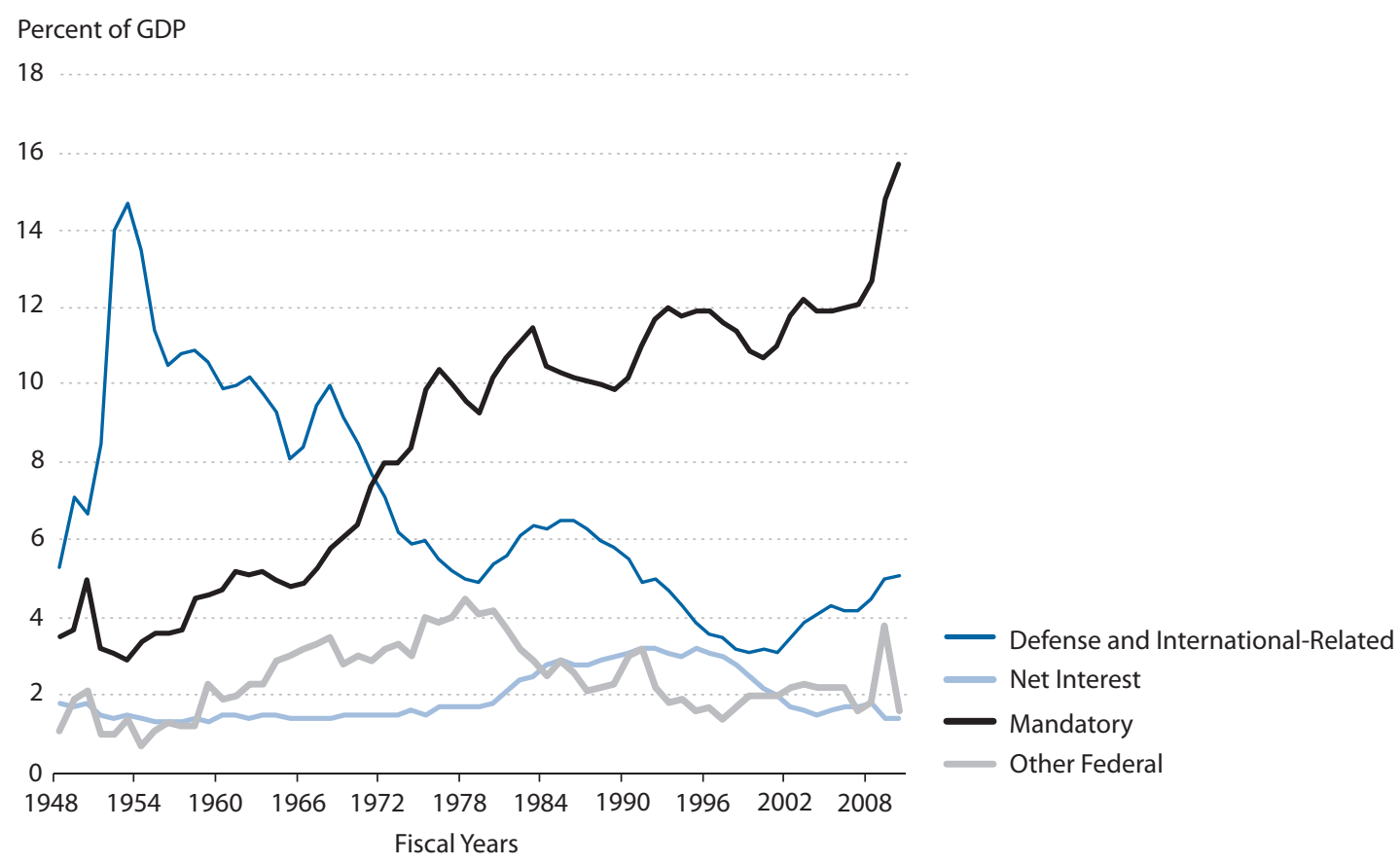

SOURCE: Office of Management and Budget.

issue. Figure 4 presents five sources of government revenue as a percent of GDP since 1948. Although total revenue as a percent of GDP has remained relatively constant since 1950 (as noted above), the figure shows the source of revenue has not. The federal government's main sources of revenue are individual income tax receipts, payroll taxes (to fund mandatory programs such as Social Security and Medicare), corporate income taxes, and excise taxes (such as those on gasoline or airfares). Individual income tax receipts and other tax receipts have been relatively constant-about 8 percent and 1 percent of GDP, respectively-but the other sources of revenue have changed considerably. Corporate income and excise taxes declined until the mid-1980s and have since remained relatively constant at about 2 percent and 1 percent of GDP, respectively. As these sources of revenue were declining, social insurance and retirement revenue increased from about 1 percent of GDP in 1948 to nearly 7 percent of GDP in late 1988 and stabilized at about that level.

The composition of government expenditures has also changed substantially. Figure 5 shows the composition of government expenditures by category since 1948. Net interest expenses and other federal spending have fluctuated around 2 percent of GDP over the period. In contrast, after increasing dramatically during the Korean War, defense and international-related spending has trended down and fluctuated in the range of 5 to 6 percent of GDP. Indeed, defense spending as a percent of GDP in 2010 (5.1 percent) is nearly identical to what it was in 1948 (5.3 percent). The large spending increases occurred in mandatory outlays, more than half of which is Social Security benefits and Medicare expenditures financed by payroll taxes paid by employ- 
ees and employers. 9 Mandatory spending increased from 3.5 percent of GDP in 1948 to nearly 16 percent of GDP in 2010. Much of the recent increase appears to be associated with the surge in unemployment benefits in the wake of the financial crisis. From December 2007 to October 2009, the unemployment rate rose from 5 percent to 10.1 percent. With a stubbornly high unemployment rate, Congress enacted several extensions of benefits for those unemployed beyond the normal 26 weeks. However, even before the financial crisis, mandatory spending had risen to 12 percent of GDP. Indeed, nearly all of the persistent deficits since 1971 can be attributed to (i) increased spending rather than a decline in revenue and (ii) the fact that the increased spending is in the mandatory component.

\section{THE ACCURACY OF THE CBO'S BUDGET PROJECTIONS}

The government's attempt to mitigate the effects of the financial crisis resulted in very large deficits in 2009 and 2010: 9.9 percent and 8.9 percent of GDP, respectively. Despite a weakerthan-expected pace of economic growth in 2011, in its August update the CBO projected that the budget deficit would fall to 8.5 percent of GDP for 2011. As previously mentioned, the CBO's January 2011 baseline projection was that the budget deficit would rise to 9.8 percent of GDP in 2011. This illustrates that reports issued less than a year apart can yield significantly different projections for the deficit.

We provide some insight into the usefulness of these projections by examining the historical accuracy of the CBO's baseline budget projections, which are typically published in January. We do not incorporate into our analysis the mid-term projections, which are typically published in the summer about the same time as the Office of Management and Budget's Mid-Session Review. Our analysis focuses on 1-year-ahead projection errors and cumulative 5-year-ahead projection errors. Five years is a reasonable planning horizon for policymakers and a period over which projections might be considered reliable. Figure 6 shows the actual and CBO-projected 5-year cumulative budget surplus/deficit as a percent of GDP. The 45-degree line denotes the points of equality between the actual and projected outcomes. If the projections were accurate, all points would fall on the 45-degree line. Consistent with our 2001 analysis, Figure 6 shows that the 5-year cumulative projections are highly inaccurate: The average absolute projection error is 2.65 percent of GDP. Moreover, most observations lie below the 45 -degree line (20 of the 30 observations are below the line), indicating a strong bias in underprojecting the deficit (overprojecting the surplus).

A common benchmark for evaluating forecast accuracy is to compare model-based forecasts with a simple random walk (RW) forecast. The latter assumes that next year's value of the forecasted series is equal to the current year's value-that is, the series cannot be forecasted beyond its current value. We compare the accuracy of the $\mathrm{CBO}$ projections relative to the projection errors from a RW projection model. The RW model projects the cumulative 5-year budget balance to be equal to the actual cumulative 5-year budget balance of the previous 5 years. In order to be operational, the $\mathrm{CBO}$ would have had to have known the cumulative budget balance over the past 5 years; however, for projections made in year $t$, the $\mathrm{CBO}$ would know only the cumulative 5 -year budget in year $t$. Hence, the RW projections made in year $t-1$ are based on the actual cumulative 5 -year budget through year $t-1$. For example, the RW cumulative 5-year deficit projections made in 1976 (i.e., the cumulative 5-year deficit projections for the period 1977 through 1981) are the actual cumulative 5-year deficit over the period 1971 through 1975. 


\section{Figure 6}

\section{Actual and CBO-Projected 5-Year Cumulative Budget Surplus/Deficit as a Percent of GDP}

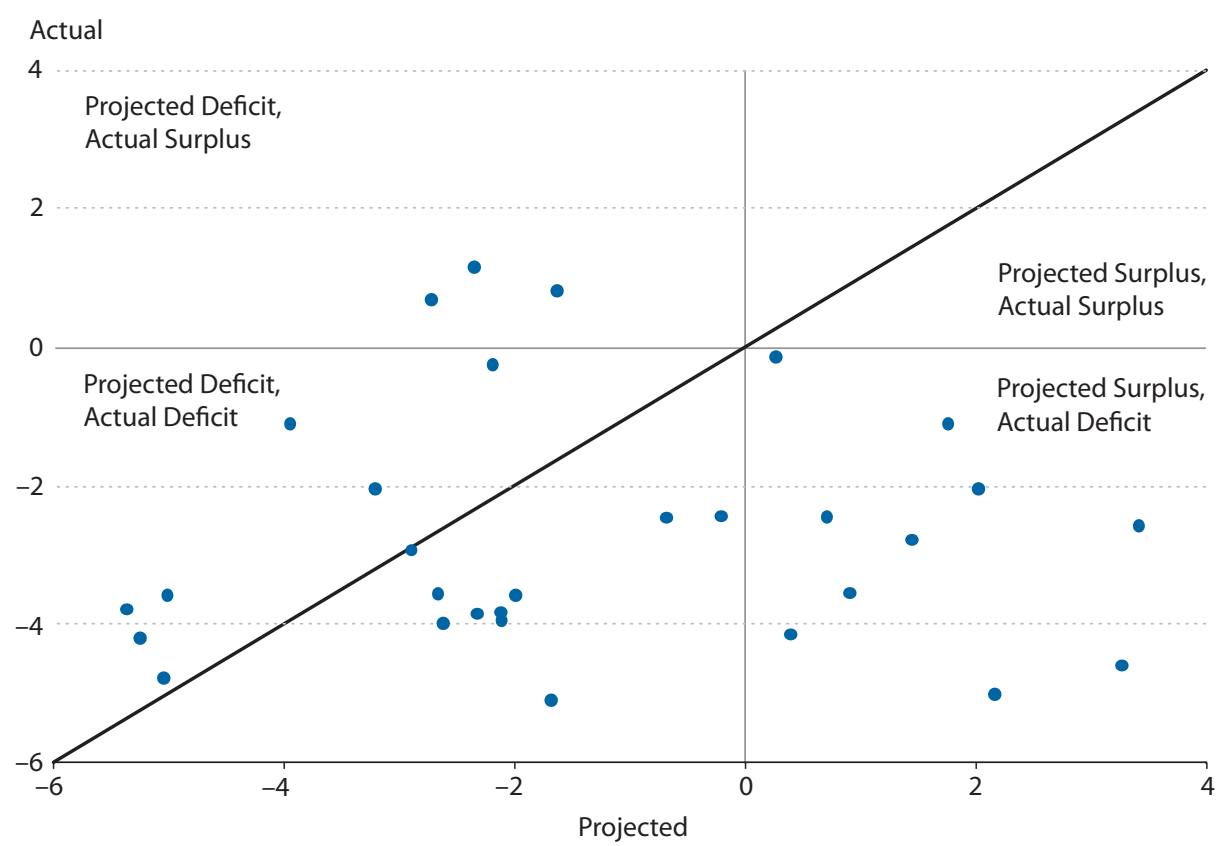

\section{Figure 7}

\section{Cumulative 5-Year Random Walk and Actual Deficit as a Percent of GDP}

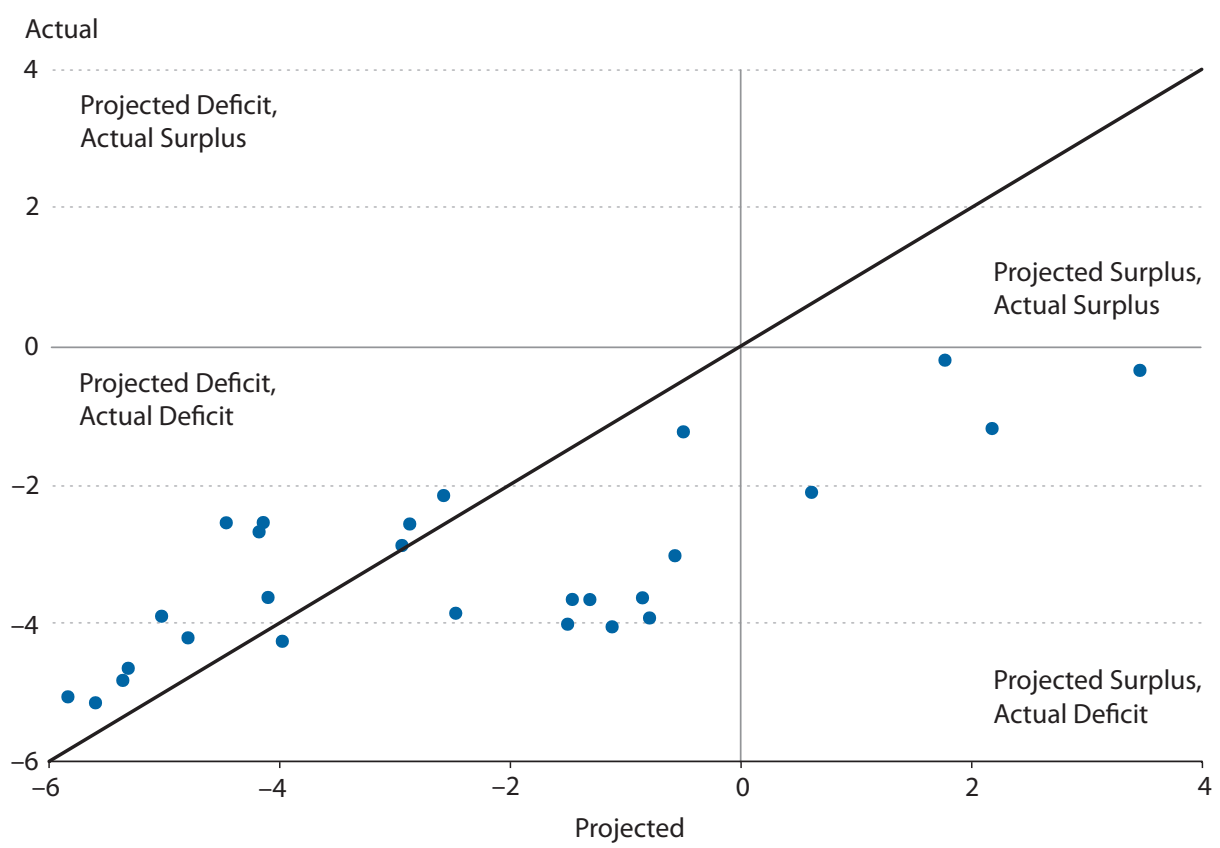




\section{Figure 8}

\section{Cumulative 5-Year Projection Errors: CBO and Random Walk Projections}

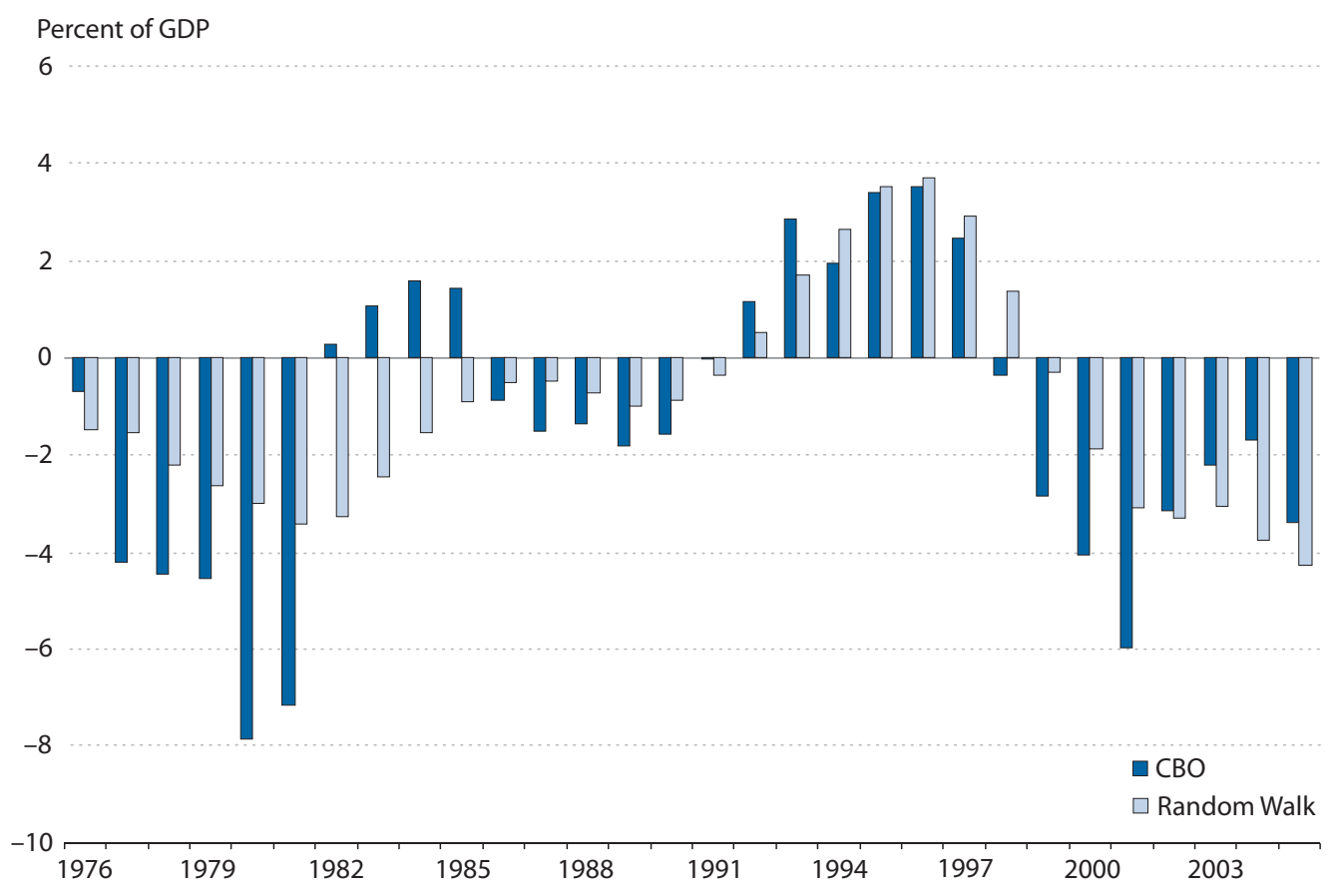

Figure 7 shows the actual and RW cumulative 5-year budget projections over our sample period. The scale is identical to that of Figure 6 to facilitate comparison of the $\mathrm{CBO}$ and RW projections. A comparison of Figures 6 and 7 suggest that, on average, the RW projections are somewhat better than the CBO's. For example, there are no observations in the upper left quadrant (projected deficit, actual surplus) and appreciably fewer observations in the bottom right quadrant (projected surplus, actual deficit) of Figure 7 compared with Figure 6. We can test whether this difference is statistically significant by calculating the root mean square projection error (RMSPE) and the mean absolute projection error (MAPE). The RMSPE and MAPE are 10.7 percent and 2.7 percent for the $\mathrm{CBO}$, compared with 5.7 percent and 2.1 percent for the RW projections. Though large, the difference in the two RMSPEs is not statistically significant at the 5 percent significance level. The difference in MAPE is smaller and likewise not statistically significant. $\underline{10}$

Figure 8 shows the $\mathrm{CBO}$ and RW cumulative 5-year projection errors for each year of the sample period. The RW projection errors have been smaller almost every year; nevertheless, the figure suggests that much of the dominance of the RW projections occurred before 1990. Since then the RW projections have been only slightly smaller than the CBO projections. The RMSPE and MAPE are 8.4 percent and 2.5 percent for the $\mathrm{CBO}$ compared with 7.1 percent and 2.3 percent for the RW. Again, these differences are not statistically significant. 


\section{Figure 9}

\section{One-Year Deficit Projection Errors as a Percent of GDP: CBO and Random Walk Projections}

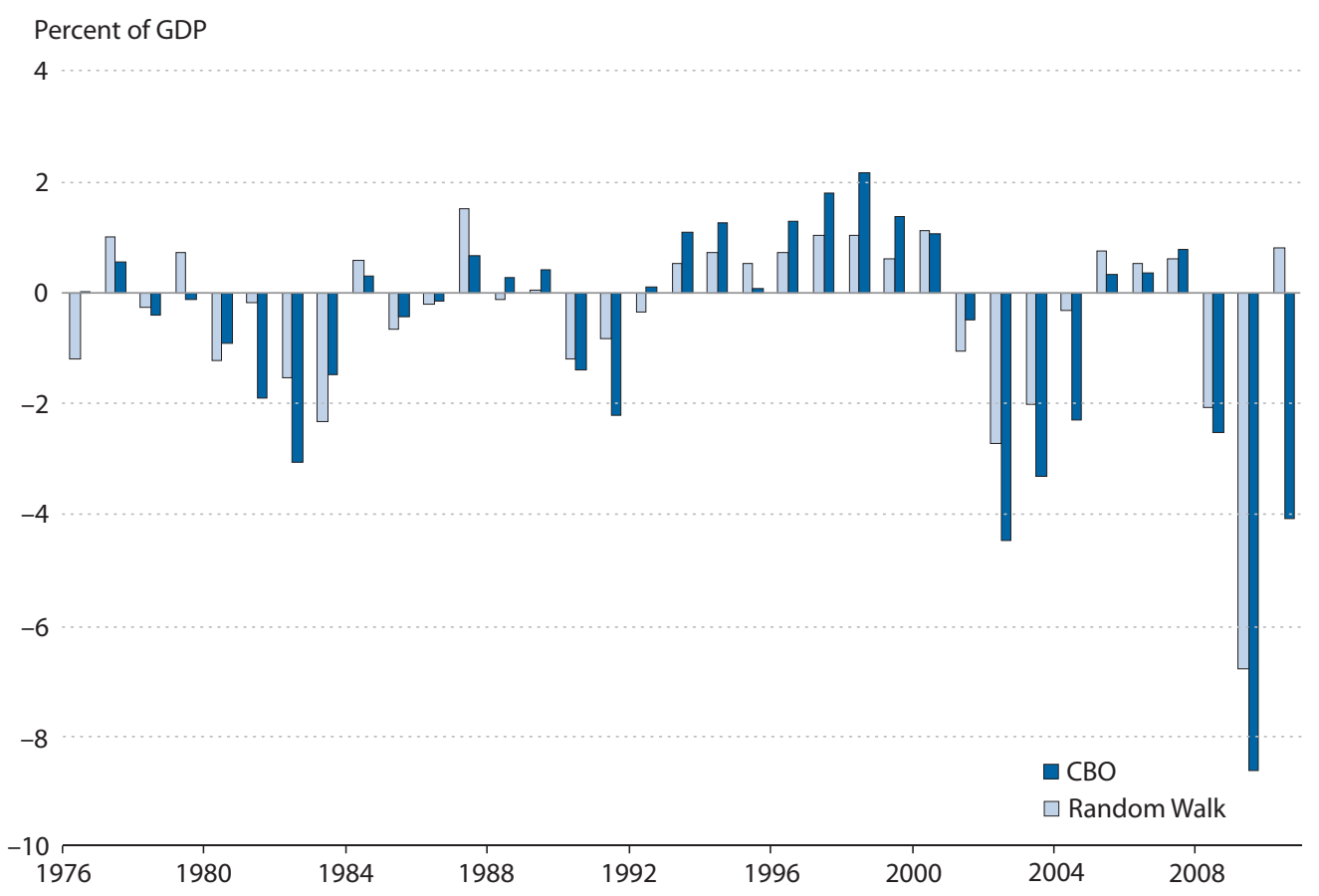

\section{Accuracy of CBO Projections One Year Ahead}

Not surprisingly, the CBO's 1-year-ahead projections are more accurate than the cumulative 5 -year projections. The relevant question, however, is this: Are they better than RW projections? Figure 9 shows the CBO and RW projection errors over the period 1976 though 2010. The figure strongly suggests that even at the 1-year projection horizon the RW model's projection errors are smaller than the CBO's. Indeed, the RMSPE and MAPE are 2.2 percent and 1.5 percent, and 1.6 percent and 1.1 percent for the $\mathrm{CBO}$ and RW projections, respectively. These differences are relatively small in absolute terms and are not statistically significant.

Of course, some of these differences are a consequence of the large errors made by the CBO (and other private forecasters) in the wake of the financial crisis. However, the RW projection errors are smaller than the CBO's even over the period 1976 through 2007-the RMSPE and MAPE are 1.6 percent and 1.1 percent, and 1.1 percent and 0.9 percent, for the $\mathrm{CBO}$ and RW projections, respectively. These results suggest that the $\mathrm{CBO}$ could have done as well by simply assuming that next year's budget surplus/deficit would be the same as last year's.

It is reasonable to believe that the relatively poor performance of the CBO's cumulative 5-year projections can be accounted for (i) by structural changes in the economy that are extremely difficult-if not impossible-to predict or (ii) swings in the government's tax and expenditure policy that are not accounted for in the baseline projections. However, the relatively poor performance of 1-year-ahead projections is more difficult to ascribe to such factors. More recently, 


\section{Supplemental Spending Hampers CBO's Budget Projections}

Typically, the CBO releases its Budget and Economic Outlook for the current FY and the next $10 \mathrm{FYs}$ at the beginning of each calendar year. These budget projections are widely followed because they provide an assessment of the medium-term budget outlook based on current law and a presumed path for the economy over the next decade. The CBO's budget projections thus depend importantly on (i) current budgetary laws that govern federal outlays and tax receipts and (ii) its own economic forecasts.

When the $\mathrm{CBO}$ publishes its budget projections for the upcoming FY, it does not know the composition of the FY 2013 budget.* Moreover, it does not know what-if any-additional federal spending in calendar year 2011 will occur that may affect the existing FY 2012 budget projections (made a year earlier). As the accompanying table shows, these additional outlays-termed supplemental appropriations-can be significant. ${ }^{\dagger}$ According to the table, supplemental appropriations were rather small from 1990 to 1998 , averaging a little less than $\$ 14$ billion per FY. However, this spending averaged about 41 percent of the average projected budget balance over the period (\$-192 billion). From 1999 to 2001 (the period when the budget surplus projections materialized), the average annual supplemental appropriation rose modestly to about $\$ 20$ billion per year, or about 10 percent of the average surplus projection. From this standpoint, it does not appear that the budget surpluses spurred Congress to undertake spending beyond what was appropriated in that year's budget.

The table shows that the largest amount of supplemental expenditures occurred from 2002 to 2009 . Over this period, the average annual supplemental appropriation was slightly less than $\$ 125$ billion per year, nearly 95 percent of the average annual projected budget deficit (\$-261 billion). These supplemental expenditures (associated with the wars in Iraq and Afghanistan and a few severe natural disasters, such as Hurricane Katrina) can help explain the CBO's relatively poor budget projections over this period.

Should Congress continue to use supplemental appropriations in the future to the same degree as it did over this period, economists, budget analysts, and policymakers would be wise to consider this development when trying to ascertain the near-term fiscal outlook provided by the CBO or the White House Office of Management and Budget. In FY 2010, though, supplemental appropriations fell by more than two-thirds from the previous year, perhaps a reflection of the public's increasing concern over the size of the federal budget deficit.

\section{Supplemental Appropriations and Initial Budget Projections}

\begin{tabular}{lccc} 
Fiscal year & $\begin{array}{c}\text { Supplemental appropriations } \\
\text { (\$ billions) }\end{array}$ & $\begin{array}{c}\text { Initial budget projection } \\
\text { (\$ billions) }\end{array}$ & $\begin{array}{c}\text { Supplemental spending as a percent of } \\
\text { initial deficit/surplus projection }\end{array}$ \\
\hline 1990 & 6.4 & -138.0 & -4.6 \\
1991 & 48.6 & -298.0 & -16.3 \\
1992 & 19.7 & -327.0 & -6.0 \\
1993 & 10.4 & -291.0 & -3.6 \\
1994 & 13.5 & -171.0 & -7.9 \\
1995 & 6.4 & -207.0 & -3.1 \\
1996 & 4.5 & -171.0 & -2.6 \\
1997 & 8.9 & -120.0 & -7.4 \\
1998 & 6.3 & -2.0 & -313.9 \\
1999 & 13.4 & 131.0 & 10.2 \\
2000 & 17.4 & 177.0 & 9.8 \\
2001 & 29.9 & 313.0 & 9.6 \\
2002 & 47.7 & -14.0 & -340.4 \\
2003 & 81.1 & -145.0 & -55.9 \\
2004 & 117.8 & -362.0 & -32.6 \\
2005 & 161.9 & -295.0 & -54.9 \\
2006 & 128.5 & -270.0 & -47.6 \\
2007 & 120.9 & -98.0 & -123.4 \\
2008 & 139.0 & -198.0 & -70.2 \\
2009 & 196.8 & -703.0 & -28.0 \\
2010 & 56.4 & -980.0 & -5.8
\end{tabular}

NOTE: Excludes rescissions. The budget projection is typically published in January of the prior year in the CBO Budget and Economic Update. SOURCE: History of Supplemental Appropriations; www.cbo.gov/publications/collections/collections.cfm?collect=3.

*Fiscal year 2013 begins on October 1, 2012, and ends on September 30, 2013.

tThese appropriations exclude rescissions, which were amounts budgeted but not spent. 


\section{Kliesen and Thornton}

the CBO's larger 1-year projections may also reflect, as noted in the shaded insert, the significant amount of supplemental expenditures after 2001.

\section{The Sensitivity of CBO Projection Errors to Economic Shocks}

This section investigates the sensitivity of $\mathrm{CBO}$ projection errors to economic shocks in two ways. First, we evaluate the CBO's projection errors by excluding recession periods. It is reasonable to assume that the CBO's near-term projection errors are heavily influenced by the behavior of the economy. The difficulty in forecasting recessions is widely acknowledged and reflected in the fact that nearly all U.S. recessions have been "called" several months after they actually began. $\frac{11}{}$ Hence, it is reasonable to assume that projection errors are considerably higher during recessions. To investigate the extent to which $\mathrm{CBO}$ projections are affected by recessions, we deleted all years with a recession during any month of the projection year. Specifically, we deleted 1980-82, 1990-91, 2001-02, and 2008-09. The RMSPE and MAPE for the non-recession years are 1.42 percent and 1.01 percent, respectively, smaller than the 1.58 percent and 1.48 percent for the period 1976-2010. Indeed, the differences in the RMSPE and MAPE between recession and non-recession years are highly statistically significant. The projections from the RW model are also larger during recession years but the difference is not statistically significant.

In the process of making its budget projections, the $\mathrm{CBO}$ forecasts certain important economic variables. It is possible that the CBO's budget errors are linked to its economic forecast errors. For example, if real GDP growth is weaker than the $\mathrm{CBO}$ forecasted, the $\mathrm{CBO}$ budget projection could be lower than projected. We investigate this possibility by regressing the CBO's budget projection errors on its forecast errors for four economic variables over the same period: real GDP growth, the unemployment rate, the 3-month T-bill rate, and the 10-year Treasury bond yield. The CBO has published its forecasts for these variables since 1984. For example, in January 1984 the CBO made economic forecasts for these variables for FY 1985. This forecast is then compared with the FY 1985 actual estimate to determine the FY 1985 forecast error. The sample period is too short to analyze the effects of forecast errors on the CBO's 5-year cumulative projections. Consequently, our analysis focuses on the 1-year-ahead projections. The economic data are based on FYs rather than calendar years. Specifically, we estimate

$$
C B O_{t}=\alpha+\delta_{1} g d p_{t}+\delta_{2} u r_{t}+\delta_{3} t b 3_{t}+\delta_{4} T 10_{t}+\varepsilon_{t},
$$

where $C B O_{t}$ denotes the CBO's 1-year-ahead budget projection error for year $t$, and $g d p_{t}, u r_{t}$, $t b 3_{t}$, and $T 10_{t}$ denote the CBO's 1-year ahead forecast errors for the growth rate of real GDP, the unemployment rate, the 3-month T-bill rate, and the 10-year Treasury bond yield, respectively.

The results are summarized in Table 1, which reports the estimated coefficients, their corresponding significance level ( $p$-value), the estimate of the adjusted $R^{2}\left(\bar{R}^{2}\right)$, and the standard error of the equation (SE). When all forecast errors are included, none of the coefficients is statistically significant at any reasonable significance level; however, each coefficient is statistically significant at at least the 10 percent significance level when considered alone. The estimate of $\bar{R}^{2}$ is very small for the T10 forecast errors and is largest for the unemployment rate. Indeed, none of the other coefficients is statistically significant when included with the unemployment rate. This point is illustrated in the last two columns of the table, which show the results when both $g d p$ 
Kliesen and Thornton

Table 1

Estimates of Equation (1) with CBO Projection Errors

\begin{tabular}{|c|c|c|c|c|c|c|c|c|c|c|c|c|}
\hline & Coef. & $p$-Value & Coef. & $p$-Value & Coef. & $p$-Value & Coef. & $p$-Value & Coef. & $p$-Value & Coef. & $p$-Value \\
\hline Constant & -0.269 & 0.285 & -0.095 & 0.815 & -0.372 & 0.338 & 0.254 & 0.502 & 0.311 & 0.455 & -0.340 & 0.369 \\
\hline$g d p$ & 0.327 & 0.270 & 0.498 & 0.023 & & & & & & & 0.176 & 0.294 \\
\hline ur & -0.497 & 0.415 & & & -1.118 & 0.000 & & & & & -0.965 & 0.000 \\
\hline$t b 3$ & 0.332 & 0.421 & & & & & 0.420 & 0.015 & & & & \\
\hline$T 10$ & -0.441 & 0.338 & & & & & & & 0.551 & 0.058 & & \\
\hline $\bar{R}^{2}$ & 0.330 & & 0.208 & & 0.375 & & 0.224 & & 0.044 & & 0.364 & \\
\hline SE & 1.358 & & 0.170 & & 1.311 & & 1.461 & & 1.622 & & 1.322 & \\
\hline
\end{tabular}

NOTE: Analysis based on annual data, 1985 to 2010. Coef., coefficient.

\section{Table 2}

Estimates of Equation (1) with Random Walk Projection Errors

\begin{tabular}{|c|c|c|c|c|c|c|c|c|c|c|c|c|}
\hline & Coef. & $p$-Value & Coef. & $p$-Value & Coef. & $p$-Value & Coef. & $p$-Value & Coef. & $p$-Value & Coef. & $p$-Value \\
\hline Constant & -0.031 & 0.887 & 0.005 & 0.985 & -0.191 & 0.375 & 0.264 & 0.197 & 0.357 & 0.155 & -0.182 & 0.402 \\
\hline$g d p$ & 0.105 & 0.569 & 0.297 & 0.054 & & & & & & & 0.052 & 0.659 \\
\hline ur & -0.470 & 0.247 & & & -0.780 & 0.000 & & & & & -0.735 & 0.001 \\
\hline$t b 3$ & 0.154 & 0.595 & & & & & 0.317 & 0.011 & & & & \\
\hline$T 10$ & -0.052 & 0.881 & & & & & & & 0.490 & 0.033 & & \\
\hline $\bar{R}^{2}$ & 0.412 & & 0.145 & & 0.464 & & 0.339 & & 0.131 & & 0.442 & \\
\hline SE & 0.806 & & 0.973 & & 1.770 & & 0.856 & & 0.980 & & 0.786 & \\
\hline
\end{tabular}

NOTE: Analysis based on annual data, 1985 to 2010. Coef., coefficient.

and $u r$ are included. Only $u r$ is statistically significant, and the estimate of $\bar{R}^{2}$ is smaller than when $u r$ is included alone, suggesting that $g d p$ has no marginal explanatory power in the presence of $u r$. A similar result holds for $t b 3$ and T10. Hence, the CBO's economic forecast errors, as summarized by the unemployment rate, appear to be related to its 1-year-ahead projection errors. Moreover, the sign of the coefficient is consistent with the idea that a higher unemployment rate than the CBO's forecast should yield a smaller surplus (or larger deficit) relative to the CBO's projection.

It is important to emphasize, however, that correlation does not imply causation - that is, it does not necessarily mean that the larger budget projection error was caused by the CBO's economic forecast error. We investigate this by repeating the analysis using the RW budget projection errors. If there is no similar relationship between the CBO's economic forecast errors and the RW budget projection errors, the hypothesis that the CBO's budget projection errors were affected by its economic forecast errors has more credibility. If, on the other hand, the results are materially similar to those using the CBO's budget projection errors, it is unlikely that the correlations reported for the CBO's budget projection errors reflect a cause-and-effect relationship between economic forecast errors and budget projection errors. 


\section{Kliesen and Thornton}

The results using the RW projection errors as the dependent variable are summarized in Table 2. All qualitative conclusions described for the CBO's projection errors apply to the RW projection errors as well. Indeed, the most notable difference is that the estimates of $\bar{R}^{2}$ are somewhat higher for the RW errors. Hence, there is no compelling evidence that the CBO's budget projections could have been materially improved had its forecasting of the unemployment rate or other economic variables been significantly better.

\section{HAS THE CBO DONE BETTER RECENTLY?}

In our previous work we evaluated the CBO's budget deficit projections over the period 1976-94. It is possible that, despite its well-known handicaps in the projection process, the CBO may have reduced its projection errors over the most recent period. To investigate this possibility we compare the CBO's 1-year-ahead projections over the periods 1976-94 and 1995-2007; 2008, 2009 , and 2010 were omitted so the results would not be affected by the unanticipated financial crisis. The RMSPE and MAPE for the latter period are 2.0 percent and 1.5 percent, respectively, compared with 1.2 percent and 0.9 percent, respectively, for the earlier period. $\frac{12}{}$ Hence, the accuracy of the CBO's projections appears to have deteriorated in the most recent period. However, despite their relatively large size, these differences are not statistically significant.

The RW projection errors are also larger over the latter period; however, the deterioration in performance is smaller. Moreover, the difference in performance between the RW and CBO projections for the most recent period is statistically significant at the 5 percent significance level for the MAPE and statistically significant at a slightly higher significance level for the RMSPE. Hence, the accuracy of the $\mathrm{CBO}$ projection has deteriorated recently both absolutely and relative to the RW benchmark. Consequently, there is no reason to place more faith in the CBO's budget projections now than there was a decade ago. If anything, the evidence suggests that slightly more skepticism of the CBO's projections in recent years may be warranted.

Essentially no change occurred in the bias of the CBO's 5-year-ahead projection errors during the most recent decade. The average underprojection of the deficit in the recent decade is 1.30 percent of GDP compared with 1.35 percent of GDP over the previous period. The 5-yearahead bias is most likely to be important since this period is a reasonable planning period of reductions in the fiscal deficit. For example, this bias suggests that deficit reduction programs that are projected to reduce the federal deficit by 1 percent of GDP over the next five years relative to the CBO's projections may miss their mark by more than 1 percent of GDP. Stated differently, the $\mathrm{CBO}$ is currently projecting the deficit to stabilize at less than 2 percent of GDP (according to the August 2011 baseline projections), but the bias suggests that the actual budget deficit could be considerably higher.

\section{DECOMPOSING THE BUDGET PROJECTION ERRORS}

It is interesting to know whether the CBO's budget projection errors are due to the relative inability to accurately project revenues or expenditures and, if so, which category of revenue or expenditures. Because cumulative 5-year projection errors overlap over time, we focus on the

1 -year forecast errors; however, the qualitative implications are similar using the cumulative 


\section{Figure 10}

\section{CBO Revenue and Expenditure Projection Errors as a Percent of GDP}

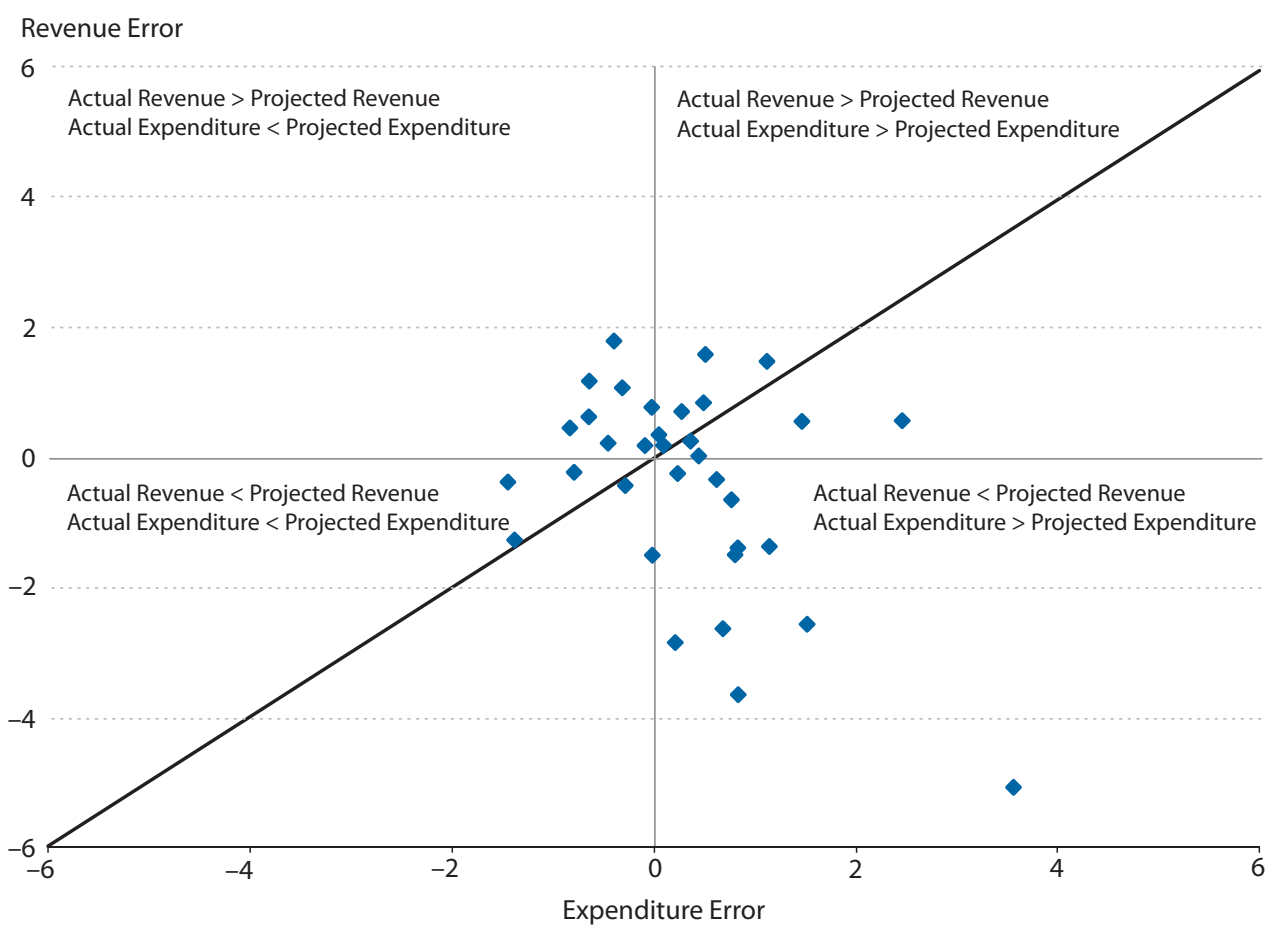

5 -year projection errors. Figure 10 shows the CBO's revenue and expenditure projection errors as a percent of GDP. The expenditure errors are plotted on the horizontal axis, while the revenue errors are plotted on the vertical axis. Points on or near the 45-degree line denote years in which the $\mathrm{CBO}$ did a good job of projecting both revenues and expenditures. Points near the horizontal zero line denote years when the $\mathrm{CBO}$ did a relatively good job of projecting revenues, while points near the vertical zero line denote years when the $\mathrm{CBO}$ did a relatively good job of projecting expenditures. Points in the upper left quadrant of the figure indicate years when the $\mathrm{CBO}$ underprojected revenue and overprojected expenditures; points in the lower right quadrant indicate the reverse.

While it is not obvious from the figure, on average the $\mathrm{CBO}$ did somewhat better in projecting expenditures. The MAPE is 1.14 percent and 0.76 percent for revenue and expenditure, respectively. The RMSPE is 1.58 percent and 1.04 percent, respectively. Hence, even though the relatively large and persistent deficits since the early 1970s are due to an increase in expenditures over revenue, the $\mathrm{CBO}$ budget projection errors are somewhat larger for revenue. Indeed, the performance difference is statistically significant at the 5 percent level for the RMSPE, but not for the MAPE. It is important to note, however, that the difference in revenue versus expenditure projection performance over the sample period is the consequence of the unusually large revenue errors associated with the recent recession. When 2008 and 2009 are deleted, the differ- 


\section{Table 3}

\begin{tabular}{|c|c|c|c|c|c|c|c|c|}
\hline & Coef. & $p$-Value & Coef. & $p$-Value & Coef. & $p$-Value & Coef. & $p$-Value \\
\hline \multicolumn{9}{|c|}{ Revenue equation } \\
\hline Constant & -0.015 & 0.521 & -0.068 & 0.392 & -0.077 & 0.756 & -0.312 & 0.298 \\
\hline IND & 1.222 & 0.000 & 1.471 & 0.000 & & & & \\
\hline CORP & 0.855 & 0.000 & & & 2.673 & 0.000 & & \\
\hline SI & 0.153 & 0.201 & & & & & 1.493 & 0.229 \\
\hline $\bar{R}^{2}$ & 0.978 & & 0.942 & & 0.550 & & 0.125 & \\
\hline SE & 0.231 & & 0.373 & & 1.042 & & 1.452 & \\
\hline \multicolumn{9}{|c|}{ Expenditure equation } \\
\hline Constant & 0.788 & 0.000 & 0.798 & 0.000 & -0.057 & 0.801 & -0.008 & 0.969 \\
\hline MAN & 0.900 & 0.000 & 0.922 & 0.000 & & & & \\
\hline DISC & 0.678 & 0.003 & & & 1.646 & 0.002 & & \\
\hline DEF & -1.023 & 0.000 & & & & & 2.005 & 0.054 \\
\hline $\bar{R}^{2}$ & 0.942 & & 0.916 & & 0.395 & & 0.202 & \\
\hline SE & 0.253 & & 0.306 & & 0.820 & & 0.941 & \\
\hline
\end{tabular}

ences in these performance measures are small and not statistically significant at any reasonable significance level.

\section{The Sources of Revenue and Expenditure Errors}

In this section, we investigate the sources of the revenue and expenditure projection errors by examining the CBO's projection errors for the major categories of revenues and expenditures. Specifically, we regressed the CBO's revenue and expenditure projection errors on three main sources of revenue and expenditures. The revenue sources are individual income taxes (IND), corporate income taxes (CORP), and social insurance taxes (SI). The expenditure sources are mandatory spending (MAN), discretionary spending (DISC), and defense spending (DEF). Regression analysis is frequently used to make statistical inferences, so it is important to emphasize that the statistics presented here are merely descriptive.

The results are summarized in Table 3. The results for the revenue error regressions are reported in the upper half of the table. The three sources of revenue errors account for 98 percent of the CBO's total revenue projection errors. However, only the coefficients on the IND and CORP are statistically significant. While each component accounts for a relatively large percentage of the CBO's revenue projection errors, errors in projecting individual tax returns appear to be the most important source of error: This error alone accounts for nearly 97 percent of the total revenue projection errors. In contrast, corporate taxes alone account for only about 33 percent of the variation in revenue errors, and social insurance projection errors account for even less: about 24 percent. 
The estimates for the expenditure errors are presented in the bottom half of Table 3. Together the three sources of error account for almost 94 percent of the total expenditure error; however, only the coefficients on discretionary and defense spending are statistically significant, suggesting that they are individually important sources of expenditure errors. $\frac{13}{1}$ This is confirmed by the fact that, individually, each accounts for about 64 percent of the total variation in the CBO's expenditure error. Hence, it appears that none of the three sources of expenditure error was more important in determining the CBO's expenditure projection errors.

Unfortunately, this analysis does not point to a specific area where the $\mathrm{CBO}$ could improve its performance as there is no particular source of revenue errors that is more important than another when the effect of the recent recession on the CBO's revenue projections is accounted for. Likewise, there is no dominant source of expenditure error.

\section{CONCLUSION}

The CBO's budget projections are widely followed by economic policymakers, investors, and other financial participants. In this paper, we analyze 34 years of $\mathrm{CBO}$ budget projections in an attempt to determine the extent to which policymakers and the public should rely on such projections. It is not our intent to malign the $\mathrm{CBO}$. Rather, our purpose is to ascertain whether the process that produces the baseline budget projections yields reasonably accurate results, given the constraints they face. Our results suggest several conclusions. First, and not surprisingly, projections for longer horizons are considerably worse than those for shorter horizons.

Second, despite the better performance at the 1-year horizon, the CBO's 1-year-ahead projection errors are not significantly better than the projection errors made by simply using the previous year's deficit/surplus as the forecast of the next year's deficit/surplus. That is, the CBO could do no worse if it made its 1-year-ahead budget projections using a RW model.

Third, the CBO's cumulative 5-year projections are considerably worse than projections from the RW model; however, none of the differences is statistically significant.

Fourth, no component of the revenue or expenditure forecasts is obviously more important than the others for either the 1-year or 5-year cumulative projections. Hence, there appears to be no area where the $\mathrm{CBO}$ could improve its overall performance by simply improving its performance in a particular revenue or expenditure category.

Fifth, the CBO's performance is significantly worse during recession years relative to nonrecession years. Hence, recessions appear to account for at least part of the CBO's relatively poor projection performance. However, the CBO's budget projections are not statistically significant from those made by the RW model during non-recession years. In a similar vein, the performance of the $\mathrm{CBO}$ relative to the simple RW does not appear to be affected by the CBO's errors in forecasting key economic variables.

Finally, we find no significant change in the CBO's budget projection performance over the past decade relative to our 2001 analysis. The CBO's projection errors are of similar magnitude and are just as biased as for the previous period. If past behavior is a guide to the future, our analysis suggests that projected future deficits will likely be larger than those currently projected. 


\section{Kliesen and Thornton}

\section{NOTES}

1 See Peach and Steindel (2000). It is important to note that at the time, long-run budget projections continued to show increasingly large deficits owing to future unfunded liabilities of the federal government's two main retirement programs (Social Security and Medicare).

$\underline{2}$ See Meyer (2000).

$\underline{3}$ The $\mathrm{CBO}$ also presents alternative projections, but these are also dependent on scenarios that may not occur. For example, the $\mathrm{CBO}$ regularly publishes projections based on the administration's annual budget and long-term budget projections based on alternative scenarios. Regarding the latter, see CBO (2011b).

4 The Budget Control Act of 2011 also included a \$2.1 trillion extension of the Treasury debt ceiling. See CBO (2011a).

$\underline{5}$ For the past several years, the $\mathrm{CBO}$ has regularly published an assessment of its economic forecasts. See, for example, the July 2010 report (www.cbo.gov/ftpdocs/115xx/doc11553/ForecastingAccuracy.pdf).

6 Indeed, the rolling correlation coefficients in a 10-year window between the two series averaged 0.4 from 1956 to 1975 and then -0.4 from 1976 to 2010.

7 PAYGO was initially enacted into law in 1990 as an amendment to the Deficit Control Act. Its purpose was to ensure that new laws changing mandatory expenditures or revenues were deficit neutral. See Heniff and Keith (2004) for a summary of various budget reform measures.

8 The cyclically adjusted budget measure is an attempt to determine how much of the deficit/surplus is due to business cycle effects that raise or lower outlays and revenues. For a discussion of the methodology, see CBO (2008).

9 Most economists believe that the burden of the payroll tax (incidence) falls almost entirely on the employee.

10 The test of the statistical significance of the difference between the $\mathrm{CBO}$ and RW projection errors is obtained by regressing the difference between the $\mathrm{CBO}$ and RW squared projection error (or absolute projection error) on a constant and testing the hypothesis that the constant term is zero. The regression used heteroskedasticity autocorrelation-consistent estimates of the standard error.

11 Since 1980, the National Bureau of Economic Research Business Cycle Dating Committee has, on average, announced the date of the beginning (peak) or end (trough) of the recession nine months after the determined date of occurrence. This lag length has varied from 6 to 12 months for these 9 episodes.

12 The results not excluding 2007-10 are larger: 3.0 percent and 2.2 percent, respectively.

13 The negative coefficient on defense spending suggests that, conditional on the other two sources of expenditure errors, the error in defense spending reduces the total expenditure error. This result is likely a consequence of the correlation between the errors. The correlations between DEF and MAN and DISC are 57 percent and 77 percent, respectively. In any event, as Table 3 shows, omitting the others results in a positive correlation between errors and defense spending and total expenditure errors.

\section{REFERENCES}

Congressional Budget Office. The Cyclically Adjusted and Standardized Budget Measures. A CBO Report, April 2008; www.cbo.gov/ftpdocs/90xx/doc9074/04-18-StandBudget.pdf.

Congressional Budget Office. CBO's Economic Forecasting Record. A CBO Report, July 2010; www.cbo.gov/ftpdocs/115xx/doc11553/ForecastingAccuracy.pdf.

Congressional Budget Office. The Budget and Economic Outlook: An Update. A CBO Report, August 2011a; www.cbo.gov/ftpdocs/123xx/doc12316/08-24-BudgetEconUpdate.pdf.

Congressional Budget Office. CBO's 2011 Long-Term Budget Outlook. A CBO Report, June 2011b; www.cbo.gov/ftpdocs/122xx/doc12212/06-21-Long-Term Budget Outlook.pdf.

Congressional Budget Office. The Budget and Economic Outlook. A Report to the Senate and House Committees on the Budget, various issues; http://www.cbo.gov/publications/bysubject.cfm?cat=0.

Heniff, Bill Jr. and Keith, Robert. "Federal Budget Process Reform: A Brief Overview." CRS Report for Congress. Congressional Research Service, Library of Congress, July 8, 2004; www.fas.org/sgp/crs/RS21752.pdf. 
Kliesen and Thornton

Kliesen, Kevin L. and Thornton, Daniel T. "The Expected Federal Budget Surplus: How Much Confidence Should the Public and Policymakers Place in the Projections?" Federal Reserve Bank of St. Louis Review, March/April 2001, 83(2), pp. 11-24; www.research.stlouisfed.org/publications/review/01//03/0103kk.pdf.

Meyer, Laurence H. "How Does a Surplus Affect the Formulation and Conduct of Monetary Policy?" Remarks before the 16th Annual Policy Conference of the National Association for Business Economics, Washington, DC, February 23, 2000; www.federalreserve.gov/boarddocs/speeches/2000/20000223.htm.

Peach, Richard and Steindel, Charles. "Summary of Observations and Recommendations." Presented at the Federal Reserve Bank of St. Louis conference, Fiscal Policy in an Era of Surpluses: Economic and Financial Implications, April 2000, pp. 1-3. 


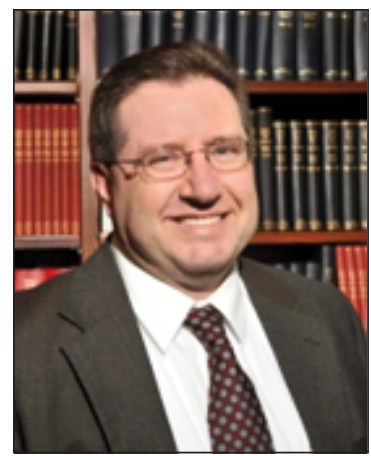

\section{Kevin L. Kliesen}

Business economist for the Supervisory Policy and Risk Analysis Unit, Federal Reserve Bank of St. Louis

http://research.stlouisfed.org/econ/kliesen/kkwp.html

\section{Research Focus}

Kevin Kliesen's research focuses on the analysis of macroeconomic conditions, the effects of energy prices on the economy, labor productivity, and fiscal policy; he also provides reports on economic and business conditions to assist the Bank president and Board of Directors.

\section{Recent Research}

"FOMC Learning and Productivity Growth (1985-2003): A Reading of the Record," Federal Reserve Bank of St. Louis Review, March/April 2010, 92(2), pp. 129-54.

"Using Brent and WTI Oil Prices to Predict Gasoline Prices,", Federal Reserve Bank of St. Louis Economic Synopses, 2011, No. 36.

"Do Oil Shocks Drive Business Cycles? Some U.S. and International Evidence," Macroeconomic Dynamics (forthcoming).

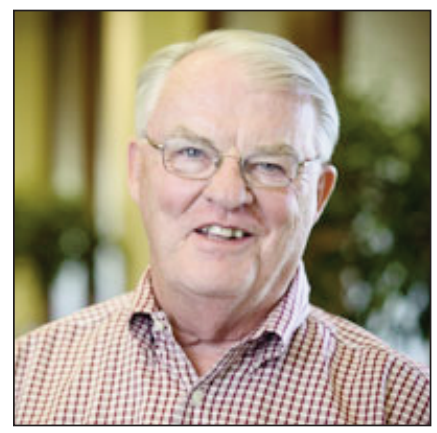

\section{Daniel L. Thornton}

Vice president and economic adviser, Federal Reserve Bank of St. Louis

http://research.stlouisfed.org/econ/thornton/

\section{Research Focus}

Dan Thornton analyzes financial markets, interest rates, and monetary policymost recently, the Fed's policy innovations of quantitative easing and the Term Auction Facility in the wake of the financial crisis.

\section{Recent Research}

"The Effectiveness of Unconventional Monetary Policy: The Term Auction Facility," Federal Reserve Bank of St. Louis Review, November/December 2011, 93(6), pp. 439-54.

"The FOMC's Interest Rate Policy: How Long Is the Long Run?" Federal Reserve Bank of St. Louis Economic Synopses, 2011, No. 29.

"A Perspective on Financial Market Reform," International Center for Banking and Corporate Governance, 2010.

"The Unusual Behavior of the Federal Funds Rate and Treasury Yields: A Conundrum or an Instance of Goodhart's Law?" Federal Reserve Bank of St. Louis Working Paper 2007-039C, updated August 2010. 